\title{
46,XX ovarian dysgenesis-short stature syndrome
}

INSERM

\section{Source}

INSERM. (1999). Orphanet: an online rare disease and orphan drug data base. $\underline{46, X X}$ ovarian dysgenesis-short stature syndrome. ORPHA:444048

A rare, genetic disorder of sex development characterized by primary amenorrhea, short stature, delayed bone age, decreased levels of estradiol, elevated levels of folliclestimulating hormone and luteinizing hormone, absent or underdeveloped uterus and ovaries, delayed development of pubic and axillary hair, and normal 46,XX karyotype. 